\title{
The First and Second Waves of the COVID-19 Pandemic in the Russian Regions: \\ Comparison of the Change in the Mortality Rate
}

\author{
Pavel V. Druzhinin* and Ekaterina V. Molchanova \\ Institute of Economics of the Karelian Research Centre of the RAS \\ Petrozavodsk, Russian Federation
}

Received 24.05.2021, received in revised form 15.06.2021, accepted 29.06.2021

\begin{abstract}
The emergence of the COVID-19 pandemic has become a new global challenge for the whole humankind affecting all spheres of society. The purpose of this article is to identify the complex effect of various factors on the mortality rate in Russian regions during the first and second waves of the coronavirus pandemic. As the information base of the study, official statistical publications («Regions of Russia», «Natural Population Movement») were used, as well as data from the official Internet resource on the situation with the incidence of COVID-19 in the regions of Russia. With the help of economic and mathematical tools, the impact of demographic, socio-economic, environmental, medical and geographical factors on the mortality rate in Russian regions was assessed. The calculations allowed to establish the causes of a significant increase in mortality in the Russian regions, as well as to identify significant differences between the first and second waves of the pandemic. The study showed that demographic and geographical factors played the leading role, but their influence at different time periods had its own characteristics. The coronavirus pandemic accelerated the process of reducing the country's population, and also caused significant damage to the Russian economy. The results of the study can be used in the field of medico-demographic policy aimed at preserving the social (population) health of the nation.
\end{abstract}

Keywords: region, COVID-19 pandemic, mortality, demography.

The article was written to fulfill the state assignment for the Institute of Economics of the Karelian Research Centre of the RAS.

Research area: economics.

Citation: Druzhinin, P.V., Molchanova, E.V. (2021). The first and second waves of the COVID-19 pandemic in the Russian regions: comparison of the change in the mortality rate. J. Sib. Fed. Univ. Humanit. Soc. Sci., 14(7), 1028-1038. DOI: 10.17516/1997-1370-0782.

\footnotetext{
(C) Siberian Federal University. All rights reserved

* Corresponding author E-mail address: pdruzhinin@mail.ru ORCID: 0000-0001-5303-0455 (Druzhinin); 0000-0003-4717-5708 (Molchanova)
} 


\title{
Первая и вторая волны пандемии COVID-19 в российских регионах: \\ сравнение изменения уровня смертности
}

\author{
П.В. Дружинин, Е.В. Молчанова \\ Институт экономики - обособленное подразделение ФИЦ \\ «Карельский научный иентр РАН» \\ Российская Федерачия, Петрозаводск
}

\begin{abstract}
Аннотация. Возникновение пандемии COVID-19 стало для всего человечества новым глобальным вызовом, который затронул все сферы жизнедеятельности общества. Цель данной статьи заключается в выявлении комплексного влияния различных факторов на уровень смертности в российских регионах во время первой и второй волн пандемии коронавируса. В качестве информационной базы исследования были использованы официальные статистические издания Федеральной службы государственной статистики (ФСГС), а также данные официального интернет-ресурса о ситуации с заболеваемостью COVID-19 в регионах России. С помощью экономико-математического инструментария выполнена оценка влияния демографических, социально-экономических, экологических, медицинских и географических факторов на уровень смертности в российских регионах. Проведенные расчеты позволили установить причины значительного роста смертности в российских регионах, а также выявить существенные различия между первой и второй волнами пандемии. Исследование показало, что ведущую роль играли демографические и географические факторы, однако их влияние в разные периоды имело свои характерные особенности. Пандемия коронавируса ускорила процесс сокращения численности населения страны, а также нанесла значительный урон экономике России. Результаты исследования могут быть использованы в области медико-демографической политики, направленной на сохранение общественного здоровья нации.
\end{abstract}

Ключевые слова: регион, пандемия COVID-19, смертность, демография.

Статья подготовлена в соответствии с государственным заданием Института экономики КарНЦ РАН.

Научная специальность: 08.00.00 - экономические науки.

\section{Введение}

Возникновение пандемии COVID-19, вызванной коронавирусом SARS-CoV-2, стало для всего человечества новым глобальным вызовом, который потребовал направить значительные ресурсы в сферу медико-биологических разработок. Важную роль в сложившейся ситуации стали играть также методы математического моделирования и искусственного интеллекта (McCall, 2020; Legido-Quigley et al., 2020; Rahmatizadeh et al., 2020). Они используются при оценке медикодемографических процессов - модели старения и смертности, модели распространения эпидемий (Sinclair, LaPlante, 2019; Topol, 2019).

Для борьбы с пандемией COVID-19 были применены различные подходы и модели. При участии сотовых операторов решались сложные задачи, связанные с распространением эпидемии в террито- 
риальном разрезе (Drew et al., 2019). Для выявления закономерностей использовалась разнообразная информация, включая данные соцсетей и загрязнения окружающей среды, карты и транспортные потоки (Shilo et al., 2020). Ряд работ был посвящен проблеме заражения вирусом в закрытых пространствах, в Китае цифровые приложения следили за контактами и соблюдением строгих карантинных мер, ограничивая транзакции для пользователей с высоким риском.

Были разработаны специальные мобильные приложения, создан контент для информационной и психологической поддержки пользователей (Wynants et al., 2020). В России у медицинского сервиса «Доктор рядом» число ежедневных телемедицинских обращений по сравнению с доковидным периодом выросло десятикратно. Таким образом, COVID-19 ускорил процессы цифровой трансформации в медицине и здравоохранении, а также необходимость разработки новых математических методов и подходов.

\section{Постановка проблемы}

Выявление факторов, которые влияют на медико-демографические показатели, важная научная задача, от решения которой зависит сохранение здоровья нации. Это имеет особое значение в кризисные периоды, так как может способствовать разработке оптимальных управленческих решений в области здравоохранения, а также повышению эффективности социальноэкономических мероприятий (Burkin et al., 2016).

Рост уровня смертности в РФ в 2020 г. в связи с пандемией способствовал появлению исследований, направленных на выявление факторов, влияющих на него. Часть из них посвящена разработке новых моделей и методик (Naumov et al., 2021). В ряде работ авторами были предложены методы определения параметров функции распределения доли инфицированных лиц новым вирусом с учетом имеющихся данных в рассматриваемом регионе (Boyarincev et al., 2020).
Для краткосрочного прогнозирования строились квадратичные и кубические функции (Gerasimenko, 2020). Развитие эпидемии также моделировалось на основе модели SEIR, в которой оценивалось несколько неблагоприятных сценариев развития ситуации, но было показано, что более жесткие сценарии позволяют резко сократить смертность (Тamm, 2020). Была предложена математическая модель для прогнозирования количества заболевших по регионам разных стран, протестированная на данных Швеции, Финляндии, США и Канады (Bychkou, 2020).

Был проведен анализ динамики развития COVID-19 с помощью обобщенного стохастического логистического уравнения для оценки числа вероятных пиков заболеваемости коронавирусом (Kokoulina et al., 2020). Данные Москвы использовались при применении агент-ориентированного подхода, что позволило учесть особенности протекания заболевания, неоднородность населения региона и социальные связи отдельных людей (Makarov et al., 2020). На основе геофизического метода был проведен сравнительный анализ информации о заболевших и умерших по России и Италии (Rodkin, 2020).

Исследователями было показано, что заболеваемость распространяется из экономически развитых регионов, таких как московский, в периферийные, менее развитые территории. В РФ в начале пандемии также было выделено еще два центра распространения вируса - Ceвер со скученностью вахтовых поселков и Северный Кавказ со слабой системой здравоохранения (Panin, 2021). На данных польских регионов был продемонстрирован быстрый рост заболеваемости и смертности в развитых центральных, контактных приграничных и приморских регионах и более благоприятная ситуация в замкнутых, депрессивных и периферийных территориях (Martynov, Sazonova, 2021). Периферийные территории потеряли значительную часть населения из-за оттока в центр, и их слабо затронула первая волна (Druzhinin, 2020). 
На основе модели диффузии инноваций по данным оперштаба ${ }^{1}$ были выделены следующие показатели - плотность населения, близость к крупнейшим агломерациям, доля мигрантов, уровень заболеваемости. Было отмечено, что в разные периоды воздействуют различные факторы (Zemcov, Baburin, 2020). На основе построенной модели распространения пандемии было проанализировано влияние социально-экономических факторов на заболеваемость COVID-19, разработана типология регионов и подтверждено, что наиболее подвержены пандемии экономически развитые регионы (Sinitsyn et al., 2020).

На региональных данных были построены регрессионные уравнения и показано отрицательное влияние на уровень смертности высокой плотности населения и положительное влияние более активного тестирования населения и более высокой температуры воздуха (Goldshteyn et al., 2020). Также была предложена регрессионная модель смертности по регионам в зависимости от активных случаев COVID-19 и обеспеченности больниц ресурсами (Stepanov, 2020).

Цель данной статьи заключается в выявлении комплексного влияния различных факторов на уровень смертности в российских регионах во время первой и второй волн пандемии COVID-19.

\section{Материалы и методы}

Данные для исследования были получены из справочников, имеющихся на сайте ФСГС, прежде всего «Регионы России» и «Естественное движение населения» Использовалась также информация официального интернет-ресурса о заболеваемо-

\footnotetext{
1 Оперативный штаб по взаимодействию профильных органов исполнительной власти был создан 27 января 2020 г. для выработки мер по предупреждению завоза и распространения новой коронавирусной инфекции на территории РФ

2 Сайт ФСГС. Режим доступа: https://rosstat.gov.ru/folder/210 (дата обращения: 01.03.2021).

3 Сайт ФСГС. Режим доступа: https://rosstat.gov.ru/folder/12781 (дата обращения: 01.03.2021).
}

сти в регионах России COVID-19 4 , однако, по оценкам экспертов, точность этих данных невелика (Rodkin, 2020; Stepanov, 2020; Tamm, 2020).

В процессе проведения исследования было собрано и проанализировано более 30 демографических, социальноэкономических, экологических, медицинских и географических показателей для 80 российских регионов. С помощью экономико-математического инструментария были построены регрессионные уравнения для оценки прироста смертности в 2020-2021 гг. относительно 2019 г. в целом и за отдельные периоды:

$$
D_{i}=A_{0}+\sum_{j=1}^{M} A_{j} \times X_{i, j},
$$

где $D_{i}$ - отношение прироста смертности в регионе $i$ в определенном периоде 20202021 гг. относительно соответствующего периода 2019 г. к численности населения региона $i ; X_{i, j}$ - показатель $j$ региона $i ; A_{0}$, $A_{j}$ - константы. При проведении расчетов рассматривались первая и вторая волны пандемии, а также их отдельные фазы. В марте 2021 г. снова начался рост смертности, но затем она снизилась, и третья волна началась в июне..

\section{Результаты исследования}

При сравнении данных ФСГС и региональных оперштабов, публикуемых в интернете, было отмечено их заметное различие. Смертность от COVID-19 в большинстве регионов, по данным ФСГС, существенно больше, чем по данным региональных оперштабов, в 32 регионах более чем в 10 раз, а в Башкортостане и Татарстане более чем в 50 раз. Видимо, желание выглядеть лучше перед федеральной властью приводило к искажению оперативной отчетности, причем именно в регионах с наиболее тяжелой ситуацией. Было выявлено, что чем выше была заболеваемость COVID-19, тем меньше был прирост смерт-

\footnotetext{
4 Официальный интернет-ресурс для информирования населения по вопросам коронавируса (COVID-19). Режим доступа: https://xn-80aesfpebagmfblc0a.xn - p1ai/ (дата обращения: 22.03.2021).
} 
ности в регионе и доля COVID-19 в общем приросте смертности (рис. 1). Поскольку информация ФСГС более надежная, то она использовалась в дальнейшем для расчетов.

Первая волна была очень высокой в Москве. В мае по уровню прироста смертности Москва была на втором месте, а в целом за первую волну - на четвертом (Московская область - на пятом). На третьем месте была Ленинградская область и на шестом - Санкт-Петербург. Высокий прирост смертности наблюдался в регионах ЦФО и ПФО, в двух, имеющих крупные агломерации, - Самарской области и Татарстане, в двух, граничащих с Московской областью, - Тульской и Тверской областях, а также в Пензенской области и Чувашии. Как уже отмечалось, из наиболее развитых центров, имеющих значительные контакты с внешним миром, пандемия перемещалась в соседние регионы. Первая волна слабо затронула периферийные регионы, в десяти из них смертность за пять месяцев даже немного снизилась, среди них Крым и Севастополь (рис. 2). Видимо, продолжались сложившиеся в предыдущие годы положительные тенденции.

Анализ коэффициентов корреляции показал, что в период первой волны наибольшее влияние оказали демографические факторы - численность населения столицы, плотность населения, численность населения региона в период роста смертности и численность населения провинции в период снижения, а также близость развитых регионов. Обеспеченность населения региона койками была значима в начале первой волны и между волнами, как и изменение доходов населения в 2020 г.

Летом стало оказывать влияние расположение региона - близость к центру, через который шли потоки отдыхающих. В августе, который разграничивает первую и вторую волны, сильнее всего воздействовала обеспеченность региона врачами. В целом за пять месяцев первой волны наибольшее влияние оказала численность населения столицы региона, расположение региона, изменение доходов населения и, существенно меньше, обеспеченность населения больничными койками. Данные по экологическим показателям по регионам за 2020 г. пока недоступны, а анализ экологических индикаторов за 2019 г. демонстрирует отсутствие значимой связи с приростом смертности в ходе пандемии COVID-19, хотя влияние загрязнений на смертность было отмечено в ряде исследований (Rybakov, Belashev, 2020).

Ослабление ограничений и рост контактов привели к значительному увеличению смертности во время второй волны. Однако Московский и Петербургский регионы теперь имели средний и низкий уровень прироста смертности, видимо, сказались имеющиеся в этих регионах ресурсы. Наиболее высокий уровень прироста смертности был в регионах ЦФО и ПФО - в Липецкой, Орловской, Самарской, Оренбургской и Рязанской областях, а также в Республике Мордовия. Немного меньшие значения фиксировались в приграничных Алтайском крае, Карелии и Омской области, а также в Кировской области. Минимальный прирост смертности был в периферийных регионах Северного Кавказа, Севера и Дальнего Востока, но уже других, чем в период первой волны (рис. 3).

Анализ коэффициентов корреляции выявил, что основное влияние опять оказали демографические факторы, но в данном случае другие - доля жителей старше трудоспособного возраста, доля пенсионеров, а также население провинции, а в период роста смертности и доля городского населения на пике смертности. Среди экономических факторов во время фазы снижения смертности, существенно выросло значение такого индикатора, как отношение между уровнем доходов населения региона и установленным прожиточным минимумом. Географический фактор близости к центру также играл важную роль. Характеристики развитости системы здравоохранения в регионах, такие как обеспеченность населения больничными койками и врачами, в наибольшей степени проявились в начале второй волны пандемии в России. За семь месяцев второй волны наиболее значимыми 
факторами влияния на уровень смертности оказались: доля лиц пенсионного возраста, географическое расположение, изменение уровня доходов населения. Влияние обеспеченности населения региона врачами проявилось в меньшей степени.

В период первой волны расчеты по формуле (1) показали, что наиболее значимы два фактора - численность населения столицы региона (чем оно больше, тем выше смертность в регионе) и суммарная смертность в граничащих регионах (учитывает контакты населения соседних регионов). Значимость изменения реальных доходов населения региона в 2020 г. и удельного количества больничных коек невелика. Остальные факторы были статистически незначимы, что связано с тем, что на восходящей и нисходящей фазах волн влияние оказывали разные показатели.

В период второй волны наиболее значимыми факторами были доля пенсионеров, расположение региона и изменение удельного количества врачей, влияние остальных факторов не было выявлено. Расположение региона определялось относительно близости к Самаре. Самарская область расположена близко к центру РФ, определенному с учетом численности населения регионов, и она имела худшую в стране ситуацию с приростом смертности в 2020 г. Надо отметить, что если вместо доли пенсионеров учитывать долю лиц старше трудоспособного возраста, то статистические характеристики немного улучшаются, но все остальные факторы становятся незначимыми.

\section{Обсуждение и заключение}

Пандемия нанесла значительный урон экономике РФ и ускорила процесс сокращения численности населения нашей страны, в 2020 г. прирост смертности в России был одним из самым больших среди экономически развитых стран.

При анализе причин столь большого роста смертности выявилась разница первой и второй волн пандемии. Определяющими были демографические и географические факторы, но разные. Первая волна началась в центрах контакта с внешним миром, в экономически наиболее развитых регионах и стала перетекать в соседние регионы. Удельное количество больничных коек во всех регионах за 30 лет уменьшилось, в некоторых в два раза, что привело к росту смертности в первые месяцы пандемии. В регионах пришлось перепрофилировать неинфекционные больницы и приспосабливать подходящие здания. Соответственно, сократилось оказание медицинской помощи при других заболеваниях, и лица старших поколений, имеющие разнообразные патологии, оказались в сложном положении, что привело к росту смертности осенью 2020 г. Отсутствие ограничений на поездки внутри страны в период летних отпусков и рост трансграничных поездок в III квартале примерно в три раза относительно II квартала привели к росту заболеваемости и смертности от COVID-19 в отдельных приграничных и центральных регионах, через которые проходят основные магистрали.

В первой волне также оказалось значимо падение уровня доходов населения. Необходимость дополнительных расходов во время пандемии и невозможность бесплатно лечиться в больнице при сокращении доходов ограничили возможности получения качественной медицинской помощи, а также привели к росту депрессивных и тревожных расстройств в условиях психологического давления в СМИ. В период второй волны стал сказываться недостаток врачей в регионах, прирост смертности был заметно меньше в регионах, где была более высокая обеспеченность населения врачами и удельное количество врачей за 30 лет возросло.

Таким образом, прирост смертности в разных регионах зависел от уровня развития здравоохранения, от географических, демографических и социально-экономических особенностей региона, которые по-разному проявлялись во время первой и второй волн пандемии. В регионах были приняты ограничения, отличавшиеся степенью жесткости, которые соблюдались населением по-разному, соответственно, 
менялась совокупность факторов, определявших прирост смертности. Проведенный анализ позволяет понять, какие последствия будут у принимаемых решений в период эпидемии в регионах в зависимости от их особенностей, и направить необхо- димые ресурсы для снижения смертности населения. Результаты исследования могут быть использованы в области медикодемографической политики, направленной на сохранение общественного (популяционного) здоровья нации.

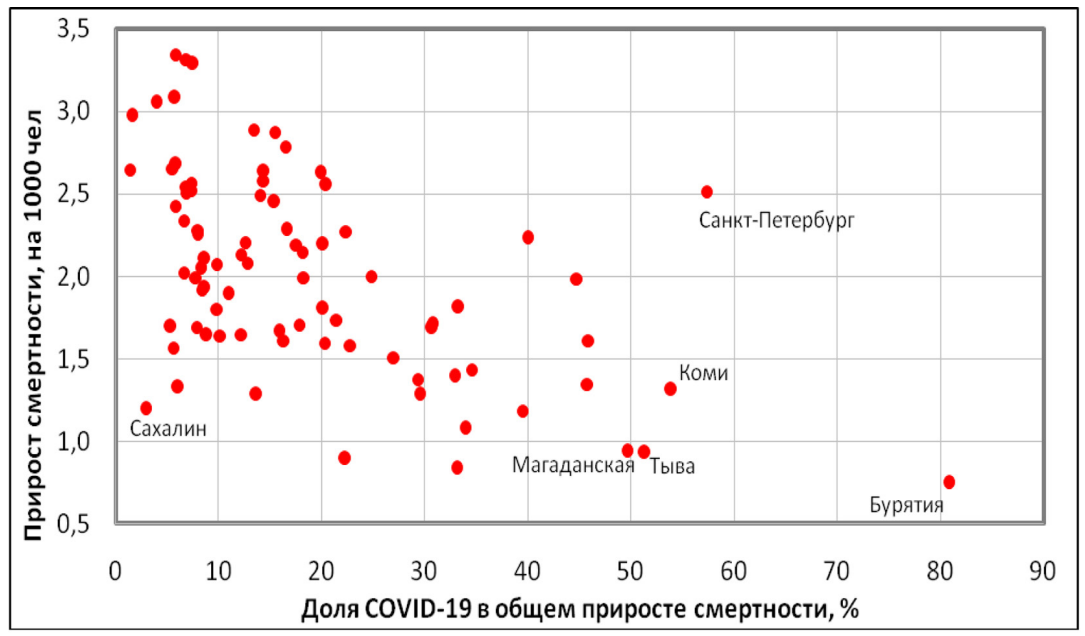

Рис. 1. Связь прироста смертности в 2020 г. относительно 2019 г. с данными региональных оперштабов по смертности от COVID-19

Fig. 1. Relation of mortality growth in 2020 relative to 2019 with data from regional stabs on mortality from COVID-19

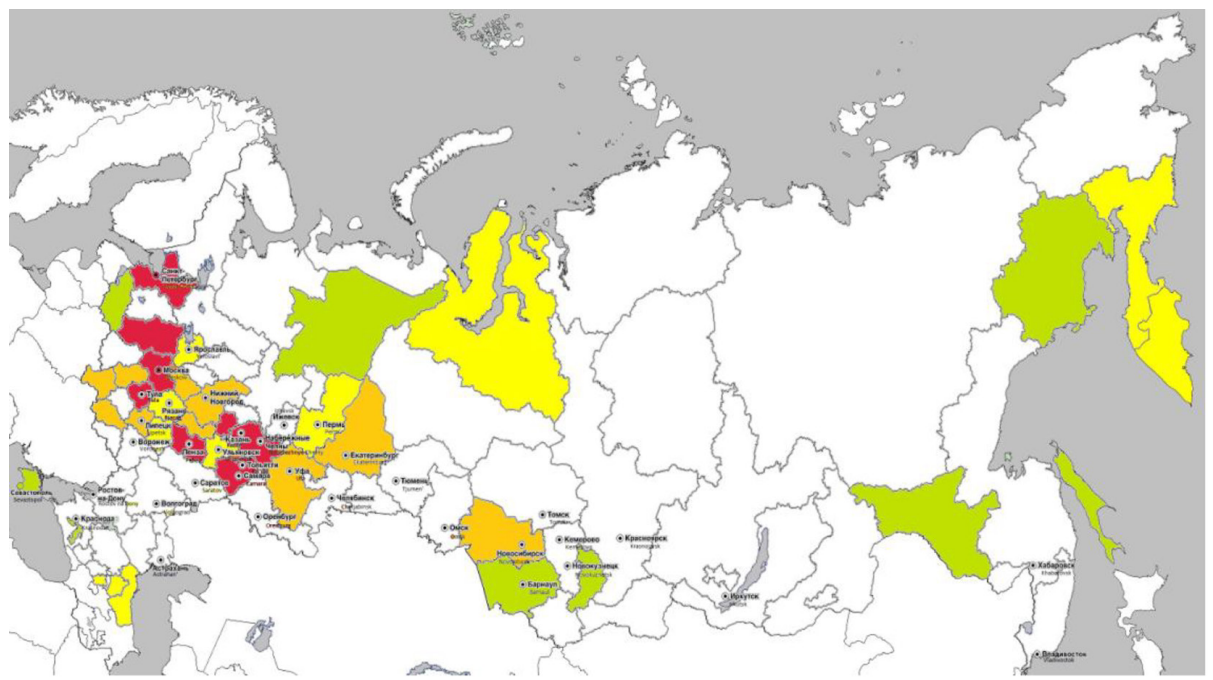

Рис. 2. Регионы с наиболее высоким (красный - прирост коэффициента смертности более 0,73 , оранжевый - от 0,59 до 0,73, желтый - от 0,45 до 0,59) и низким (зеленый) приростом смертности во время первой волны 2020 г.

Fig. 2. The regions with the highest (red - an increase in the mortality rate of more than 0,73 , orange - from 0,59 to 0,73 , yellow-from 0,45 to 0,59 ) and the lowest (green) increase in mortality during the first wave of 2020 


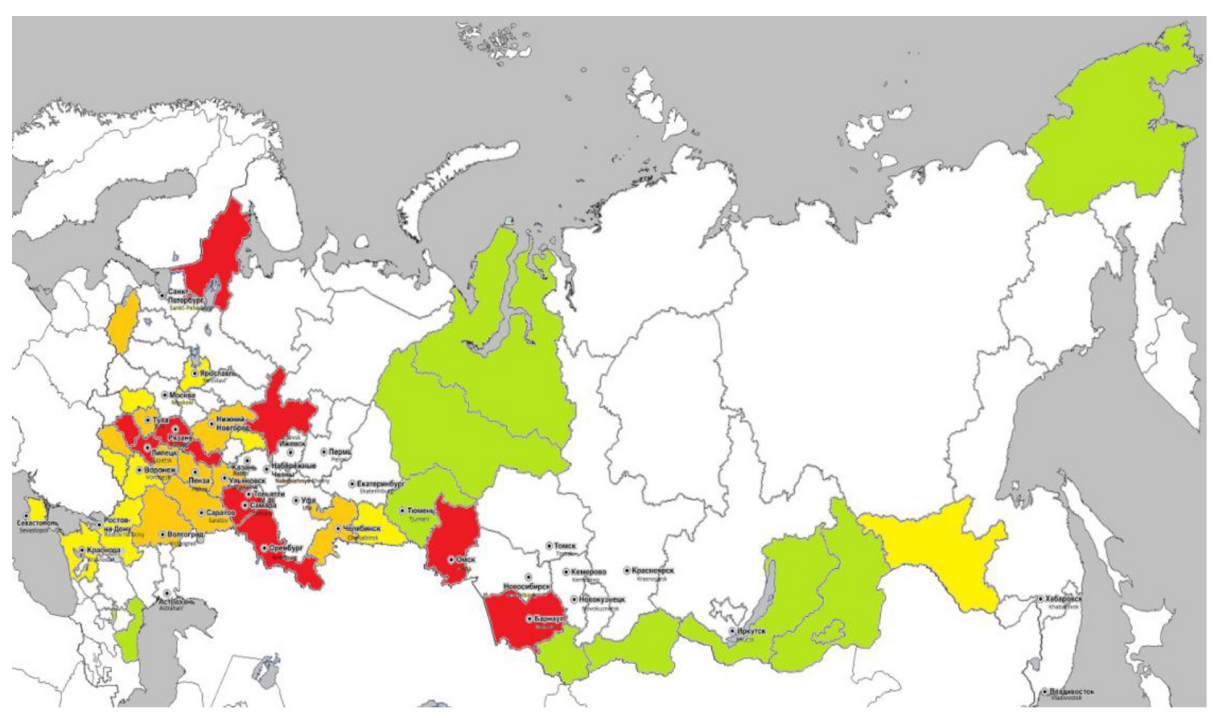

Рис. 3. Регионы с наиболее высоким (красный - прирост коэффициента смертности более 2,86, оранжевый - от 2,71 до 2,86, желтый - от 2,45 до 2,71) и низким (зеленый) приростом смертности во время второй волны 2020-2021 гг.

Fig. 3. The regions with the highest (red - an increase in the mortality rate of more than 2,86 , orange - from 2,71 to 2,86, yellow-from 2,45 to 2,71) and the lowest (green) increase in mortality during the second wave of 2020-2021

Таблица 1. Результаты расчетов параметров зависимости (1) прироста смертности (на млн чел.) за первую и вторую волны COVID-19 относительно соответствующих периодов 2019 г.

Table 1. The results of calculations of the parameters of the dependence of (1) the increase in mortality (per million people) for the first and second waves of COVID-19 relative to the corresponding periods of 2019

\begin{tabular}{|c|c|c|}
\hline Показатель & $\begin{array}{l}\text { Март } 2020 \text { г. - } \\
\text { июль } 2020 \text { г. }\end{array}$ & $\begin{array}{l}\text { Август } 2020 \text { г. - } \\
\text { февраль } 2021 \text { г. }\end{array}$ \\
\hline A & $1733,9 *$ & $-111,8 * * *$ \\
\hline $\begin{array}{l}\text { Суммарный уровень прироста смертности } \\
\text { в соседних регионах, на млн чел. }\end{array}$ & $86,8 * * *$ & - \\
\hline Население столицы, тыс. чел. & $0,055 * * *$ & - \\
\hline Изменение реальных доходов населения в 2020 г.,\% & $-13,3$ & - \\
\hline Количество больничных коек, на 10 тыс. жителей & 2,67 & - \\
\hline Численность пенсионеров на 1000 жителей & - & $10,5^{* * *}$ \\
\hline Отклонение расположения столицы региона от $53^{\circ}$ с. ш. & - & $-34,4 * *$ \\
\hline Отклонение расположения столицы региона от $50^{\circ}$ в. д. & - & $-4,74 * * *$ \\
\hline Изменение удельного количества врачей за 1990-2019 г.,\% & - & $-5,6^{* *}$ \\
\hline Численность населения в провинции, тыс. чел. & - & 0,052 \\
\hline $\mathrm{R}^{2}$ & 0,36 & 0,59 \\
\hline $\mathrm{p}$ & 0,00000 & 0,00000 \\
\hline
\end{tabular}

${ }^{* * *} p<0.01,{ }^{* *} p<0.05,{ }^{*} p<0.1$. 


\section{Список литературы}

Бояринцев, В.В., Пальмин, Р.С., Пальмин, С.А., Перцев, С.Ф. (2020). Метод прогнозирования параметров эпидемического процесса, вызванного COVID-19 // Кремлевская медицина. Клинический вестник, 2, 14-21.

Буркин, М.М., Молчанова, Е.В., Кручек, М.М. (2016). Интегральная оценка влияния социальноэкономических и экологических факторов на региональные демографические процессы // Экология человека, 6, 39-46. DOI: 10.33396/1728-0869-2016-6-39-46

Бычков, А.В. (2020). Информационная система глобального мониторинга для эпидемиологов (на материале Big Data o COVID-19) // Клиническая инфектология и паразитология, 9, 4, 386404.

Герасименко, П.В. (2020). Моделирование и прогнозирование показателей динамики заболевания жителей регионов коронавирусом COVID-19 // Транспортные системы и технологии, 6, 4, 88-91. DOI: 10.17816/transsyst20206488-97.

Гольдштейн, Э.М. (2020). Факторы, влияющие на смертность от новой коронавирусной инфекции в разных субъектах Российской Федерации // Журнал микробиологии, эпидемиологии и иммунобиологии РФ, 97, 6, 604-607. DOI: 10.36233/0372-9311-2020-97-6-11.

Дружинин, П.В. (2020). Концентрация населения в столицах регионов Европейского Севера // Пятая международная научная конференция «Арктика: история и современность». СанктПетербург, 539. DOI: 10.1088/1755-1315/539/1/012082.

Земцов, С.П., Бабурин, В.Л. (2020). COVID-19: пространственная динамика и факторы распространения по регионам России // Известия Российской академии наук. Серия географическая, $84,4,485-505$.

Кокоулина, М.В., Епифанова, А.С., Пелиновский, Е.Н., Куркина, О.Е., Куркин, А.А. (2020). Анализ динамики распространения коронавируса с помощью обобщенной логистической модели // Труды НГТУ им. Р.Е. Алексеева, 3 (130), 28-41. DOI: 10.46960/1816-210Kh_2020_3_28

Макаров, В.Л., Бахтизин, А.Р., Сушко, Е.Д., Агеева, А.Ф. (2020). Моделирование эпидемии COVID-19 - преимущества агент-ориентированного подхода // In Экономические и соииальные перемены: факты, тенденции, прогноз, 13, 4, 58-73. DOI: 10.15838/esc.2020.4.70.3.

Мартынов, В.Л., Сазонова, И.Е. (2021). Территориальные особенности демографического развития в Польше под воздействием пандемии COVID-19 // Псковский регионологический журнал, 1 (45), 37-45. DOI: 10.37490/S221979310013636-2.

Наумов, С.Н., Швец, Ю.Ю., Гретченко, А.А. Оценка дополнительной смертности населения в рамках пандемии COVID-19 // Научно-аналитический журнал «Наука и практика» РЭУ им. Г.В. Плеханова, 13, 1, 74-84.

Панин, А.Н., Рыльский, И.А., Тикунов, В.С. (2021). Пространственные закономерности распространения пандемии COVID-19 в России и мире: картографический анализ // Вестник Московского университета. Серия 5. География, 1, 62-77.

Родкин, M.B. (2020). О статистике развития эпидемии COVID-19 в России и Италии, попытка прогноза методами математической геофизики // Уральский геологический журнал, 2 (134), 3-12.

Рыбаков, Д.С., Белашев, Б.З. (2020). Погодно-климатические условия, загрязнение атмосферного воздуха, вызовы скорой медицинской помощи и смертность населения в Петрозаводске // Экология человека, 5, 21-30. DOI: 10.33396/1728-0869-2020-5-21-30.

Степанов, В.С. (2020). Зависимость уровня смертности в регионах от распространенности активных носителей SARS-COV-2 и ресурсов организаций здравоохранения // Анализ риска здоровью, 4, 12-22. DOI: 10.21668/health.risk/2020.4.02.

Тамм, М.В. (2020). Коронавирусная инфекция в Москве: прогнозы и сценарии // ФАРМАКОЭКОНОМИКА. Современная фармакоэкономика и фармакоэпидемиология, 13 (1), 43 51. DOI: $10.17749 / 2070-4909.2020 .13 .1 .43-51$. 


\section{References}

Boyarincev, V.V., Pal'min, R.S., Pal'min, S.A., Percev, S.F. (2020). Metod prognozirovaniya parametrov e'pidemicheskogo processa, vy'z vannogo COVID-19 [Method for predicting parameters of epidemic process caused by COVID-19]. In Kremlevskaya medicina. Klinicheskij vestnik [Kremlin medicine. Clinical Bulletin], 2, 14-21.

Burkin, M.M., Molchanova, E.V., Kruchek, M.M. (2016). Integral'naya ocenka vliyaniya social'noekonomicheskih i ekologicheskih faktorov na regional'nye demograficheskie processy [Integrated assessment of the impact of socio-economic and environmental factors on regional demographic processes]. Ekologiya cheloveka [Human ecology], 6, 39-46. DOI: 10.33396/1728-0869-2016-6-39-46

Bychkou, A.V. (2020). Informacionnaya sistema global'nogo monitoringa dlya e'pidemiologov (na materiale Big Data on COVID-19) [Global monitoring information system for epidemiologists (on the material of Big Data on COVID-19)]. In Klinicheskaya infektologiya i parazitologiya [Clinical infectology and parasitology], 9, 4, 386-404.

Drew, D.A., Nguyen, L.H., Steves, C.J., Menni, C., Freydin, M., Varsavsky, T. (2020). COPE Consortium. Rapid implementation of mobile technology for real-time epidemiology of COVID-19. Science 2020 Jun 19; 368(6497): 1362-1367.

Druzhinin, P.V. (2020). Naseleniye Evropeyskogo Severa: kontsentratsiya v stolitsakh regionov [The population of the European North: concentration in the capitals of the regions]. In Seriya konferentsiy IOP: Nauka o Zemle i okruzhayushchey srede. 5-ya Mezhdunarodnaya konferentsiya "Arktika: istoriya i sovremennost» [Conference Series: Earth and Environmental Science, 5th International Conference "Arctic: History and Modernity»]. Sankt-Peterburg, 539. DOI: 10.1088/1755-1315/539/1/012082.

Gerasimenko, P.V. (2020). Modelirovaniye i prognozirovaniye pokazateley dinamiki zabolevaniya zhiteley regionov koronavirusom COVID-19 [Modeling and forecasting indicators of disease dynamics in the regions with coronavirus COVID-19]. In Transportnyye sistemy i tekhnologii [Transport systems and technologies], 6, 4, 88-91. DOI: 10.17816/transsyst20206488-97.

Goldshteyn, E.M. (2020). Faktory. vliyayushchiye na smertnost ot novoy koronavirusnoy infektsii v raznykh subyektakh [Factors. affecting mortality from a new coronavirus infection in different subjects of the Russian Federation]. In Zhurnal mikrobiologii. epidemiologii i immunobiologii RF [Journal of Microbiology. epidemiology and immunobiology], 97, 6, 604-607. DOI: 10.36233/0372-9311-2020-97-6-11.

Kokoulina, M.V., Epifanova, A.S., Pelinovskiy, E.N., Kurkina, O.E., Kurkin, A.A. (2020). Analiz dinamiki rasprostraneniya koronavirusa s pomoshchyu obobshchennoy logisticheskoy modeli [Analysis of the dynamics of coronavirus distribution using a generalized logistic model]. In Trudy NGTU im. R. E. Alekseyeva [Proceedings of NSTU named after R. E. Alekseev], 3 (130), 28-41.

Legido-Quigley, H., Asgari, N., Teo, Y.Y., Leung, G.M., Oshitani, H., Fukuda, K., et al. (2020). Are high-performing health systems resilient against the COVID-19 epidemic? In The Lancet. Mar; 395 (10227): $848-850$.

Makarov, V.L., Bakhtizin, A.R., Sushko, E.D., Ageyeva, A.F. (2020). Modelirovaniye epidemii COVID-19 - preimushchestva agent-oriyentirovannogo podkhoda [Modeling of the COVID-19 epidemic - the advantages of an agent-oriented approach]. In Ekonomicheskiye $i$ sotsialnyye peremeny: fakty, tendentsii, prognoz [Economic and social changes: facts. trends. forecast], 13, 4, 58-73. DOI: 10.15838/ esc.2020.4.70.3.

Martynov, V.L., Sazonova, I.E. (2021). Territorialnyye osobennosti demograficheskogo razvitiya v Polshe pod vozdeystviyem pandemii SOVID-19 [Territorial features of demographic development in Poland under the influence of the pandemic COVID-19]. In Pskovskiy regionologicheskiy zhurnal [Pskov Regional Journal], 1 (45), 37-45. DOI: 10.37490/S221979310013636-2.

McCall, B. (2020). COVID-19 and artificial intelligence: protecting health-care workers and curbing the spread. In The Lancet Digital Health. Apr; 2(4): e166-e167.

Naumov, S.N., Shvets, Yu. Yu., Gretchenko, A.A. (2021). Otsenka dopolnitelnoy smertnosti naseleniya $\mathrm{v}$ ramkakh pandemii COVID-19 [Assessment of additional mortality of the population as part of the 
pandemic COVID-19]. In Nauchno-analiticheskiy zhurnal Nauka i praktika Rossiyskogo ekonomicheskogo universiteta im. G.V. Plekhanova [Scientific and analytical journal Science and Practice of the Russian University of Economics named after G. V. Plekhanov], 13, 1, 74-84.

Panin, A.N., Rylskiy, I.A., Tikunov, V.S. (2021). Prostranstvennyye zakonomernosti rasprostraneniya pandemii COVID-19 v Rossii i mire: kartograficheskiy analiz [Spatial patterns of the spread of the pandemic COVID-19 in Russia and the world: cartographic analysis]. In Vestnik Moskovskogo universiteta. Seriya 5: Geografiya [Bulletin of Moscow University. Series 5: Geography], 1, 62-77.

Rahmatizadeh, S., Valizadeh-Haghi, S., Dabbagh, A. (2020). The role of artificial intelligence in management of critical COVID-19 patients. In Journal of Cellular \& Molecular Anesthesia 2020. Apr; 5(1):16-22.

Rodkin, M.V. (2020). O statistike razvitiya epidemii COVID-19 v Rossii i Italii. popytka prognoza metodami matematicheskoy geofiziki [On statistics on the development of the epidemic COVID-19 in Russia and Italy. attempt to predict by methods of mathematical geophysics]. In Uralskiy geologicheskiy zhurnal [Ural Geological Journal], 2 (134), 3-12.

Rybakov, D.S., Belashev B.Z., (2020). Pogodno-klimaticheskiye usloviya. zagryazneniye atmosfernogo vozdukha. vyzovy skoroy meditsinskoy pomoshchi i smertnost naseleniya v Petrozavodske [Weather and climatic conditions, air pollution, emergency medical challenges and mortality in Petrozavodsk]. In Ekologiya cheloveka [Human ecology], 5, 21-30. DOI: 10.33396/1728-0869-2020-5-21-30.

Sinclair, D.A., LaPlante, M.D. (2019). Lifespan. Why We Age - and Why We Don't Have To. London, Thorsons, $320 \mathrm{p}$.

Sinitsyn, E.V., Tolmachev, A.V., Ovchinnikov, A.S. (2020). Sotsialno-ekonomicheskiye faktory rasprostraneniya SARS-COV-2 po regionam Rossii [Socio-economic factors of the spread of SARS-COV-2 across the regions of Russia]. In R-economy [R-economy], 6(3), 129-145. DOI: 10.15826/recon.2020.6.3.011.

Shilo, S., Rossman, H., Segal, E. (2020). Axes of a revolution: challenges and promises of big data in healthcare. In Nat Med 2020. Jan; 26(1): 29-38.

Stepanov, V.S. (2020). Zavisimost' urovnya smertnosti v regionakh ot rasprostranennosti aktivnykh nositelej SARS-CoV-2 i resursov organizacij zdravookhraneniya [The dependence of mortality rates in regions on the prevalence of active SARS-CoV-2 carriers and the resources of health organizations]. In Analiz riska zdorov'yu [Health risk analysis], 4, 12-22. DOI: 10.21668/health.risk/2020.4.02.

Tamm, M.V. (2020). Koronavirusnaya infekciya v Moskve: prognozy i scenario [Coronavirus infection in Moscow: predictions and scenarios]. In Farmakoehkonomika. Sovremennaya Farmakoehkonomika i Farmakoehpidemiologiya [Pharmacoeconomics. Modern Pharmacoeconomics and Pharmacoepidemiology], 13 (1), 43-51. DOI: 10.17749/2070-4909.2020.13.1.43-51.

Topol, E.J. (2019). Deep Medicine. How Artificial Intelligence Can Make Healthcare Human Again. New York, Basic Books, 400 p.

Topol, E.J. (2019). High-performance medicine: the convergence of human and artificial intelligence. In Nat Med 2019. Jan; 25(1):44-56.

Wynants, L., Van Calster, B., Collins, G.S., Riley, R.D., Heinze, G., Schuit, E., et al. (2020). Prediction models for diagnosis and prognosis of covid-19 infection: systematic review and critical appraisal. In $B M J$ 2020. Apr 07; 369: m1328.

Zemcov, S.P., Baburin, V.L. (2020). COVID-19: Prostranstvennaya dinamika i faktory rasprostraneniya po regionam Rossii [COVID-19: Spatial dynamics and distribution factors in the regions of Russia]. In Izvestiya RAN [Izvestia RAS. Serias geographical], 84, 4, 485-505. 